\title{
A LINGUAGEM E SUAS TRAMAS
}

\section{Moema de Castro e Silva Olival*}

A linguagem é a morada do ser.

HEIDEGGER

\section{RESUMO}

O presente ensaio visa discutir a problemática do enfoque do literário e, nele, o papel da linguagem.

Recebi um repto. Respondo a ele.

Poeta renomado, José Godoy Garcia, também romancista, aventura-se, agora, pelo terreno dos contos. Seu livro Florismundo Periquito chegou-me com uma dedicatória desafiadora:

À mestra Moema de Castro e Silva Olival, este livro que só teve um interesse, que é o talvez essencial interesse ficcional: criar almas.

Procurei muito a forma satírica, muito embora, contra minha vontade, tenha encontrado excessiva forma dramática. Ninguém poderá lucidamente dizer: aqui está uma linguagem, tal a desimportância dela diante das figuras humanas que busquei recriar.

Percorri as páginas de Florismundo Periquito. Busquei num desafogo de consciência - ilusória tentativa de concordar com o autor - detectar a "desimportância da linguagem", no impacto de vida que delas se depreende. Em vão! Esforço inútil! Como percebê-lo senão através da linguagem? Como apreender os estigmas das figuras humanas, os retalhos condensados de emoção e desacertos que configuram a paisagem do ser vivente, na caminhada para a Terra de Promissão, os estilhaços da alma e da vontade senão através da linguagem?

\footnotetext{
- Doutora em Letras Clássicas e Vernáculas pela Universidade de São Paulo. Professora Titular aposentada do Departamento de Letras da UFG.
} 
O impacto deveria estar, então, na diversidade do conceito de linguagem por parte do escritor, fato desde o início suspeitado por nós desde a época de sua conferência pronunciada no correr da II Semana de Literatura Goiana, em maio de 1990, no Instituto de Ciências Humanas e Letras, da UFG.

Senão vejamos.

Hoje, entendemos por linguagem da obra tudo que, nesta obra, significa, até o próprio silêncio, bem como os estratos simbólicos, imagéticos, psicossociológicos, históricos, místicos etc., que a compuserem, sendo a obra encarada como um todo, um cosmos universal uno, regido por suas próprias leis e - relevante notar-como uma obra de arte a ser fruída pelo leitor a quem cabe a respectiva decodificação criativa, objeto da estética da recepção. Mas, importante lembrar, conterá um momento histórico de uma consciência criadora. A adesão a esse momento poderá representar o nascimento de uma escritura ${ }^{1}$ que irá caracterizar aquela obra, no espaço e no tempo. E será o estilo a varinha mágica a ordenar os elementos desse cosmos que se corporificará através da Linguagem Literária.

Se, como afirma Roberto Schwarz, ${ }^{2}$ a vida é uma linguagem, pesquisá-la e recriá-la, pela literatura, já é tarefa de uma metalinguagem, ou, melhor, de uma linguagem especial.

Então, o escritor, ao escrever um texto literário, cria a realidade ficcional de acordo com sua visão de mundo, sua sensibilidade, sua imaginação, sua percepção crítica e a expressa para que possa concretizar essa realidade e torná-la perceptível. Como? Através da linguagem que será o vetor do ato de criação, reconhecida como um todo, como a forma - entendida em sua conceituação moderna - e que seria constituída pela interação dinâmica de expressão e conteúdo. Aliás, só neste sentido, podemos entender o pensamento de Croce: "Arte é forma, nada mais que forma". ${ }^{3}$

Entender, como a retórica antiga, que a linguagem da obra é só expressão, é só seu léxico, é só sua sintaxe, é só sua semântica é mutilar a obra em seus elementos vitais, é cortar-lhe o dinamismo dos processos inter-relacionais: expressão e conteúdo, responsáveis pelo núcleo dinâmico da criatividade, responsável, pois, pelo seu potencial criativo. 
Não se pode falar em trama, em "ponto nodal" ou em conflito, como diz José Godoy Garcia, sem imaginar que é pela e na linguagem que estes elementos se articulam e se expressam.

E esta nos parece a grande atitude da crítica moderna. Avaliar a capacidade de arregimentação trazida a lume através da linguagem da obra, monitorizada por uma voz narradora em que se detectará não só o momento da consciência histórica de seu criador, principalmente através do autor-implícito, mas ainda, os critérios de organização responsáveis pela tensão discurso-diegese, por exemplo, e que respondem pela dinamicidade da leitura, ou pela articulação do seu universo míticoalegórico-simbólico, enfim, por todos os princípios básicos apontados quando tentamos definir a referida linguagem. Também, nesta atividade de avaliar a capacidade de arregimentação, buscar-se-á a participação ainda do leitor, na medida em que o humanismo dos questionamentos contidos na obra o envolvem como ser humano. E, de repensá-los, virá seu crescimento como ser. Assim torna-se uma crítica de interpretação, de análise, de avaliação e de recriação.

Portanto, uma práxis mais moderna e ativa do que apenas visar à fruição da obra, ainda que esta fruição faça parte das exigências da produção estética. Só que será uma fruição ativa, indagadora, questionadora.

Ana Hatherly ${ }^{4}$ nos diz: "Um dos aspectos característicos da Crítica Moderna é considerar que a verdadeira leitura é a leitura crítica."

Nesta "mudança do olhar", a crítica literária, tal como a expusemos acima, deverá desentranhar e mesmo rediscutir quaisquer referências, ou indícios ou perspectivas daquele corpus examinado, mesmo que estejam dissimuladamente articuladas nas tramas de sua linguagem.

Voltando ao nosso ponto de discussão, para o nosso autor, pelo visto, uma expressão simples faz correrem paralelos a expressão (tomada em sentido retórico, superficial) e o conteúdo, quando, na verdade, são faces de uma mesma moeda, formam um todo amalgamado no processo da interação expressão-conteúdo, sendo então que o nível simples da expressão, no caso, deverá estar significando, traduzindo proposta articulada pelo conteúdo, no momento do ato criador.

Seu último livro em prosa, Florismundo Periquito, poderá ser um exemplo eloqüente desta argumentação. Aparentemente despretensioso, arrola, no seu sumário, onze contos. Dentre eles, "Florismundo Periquito" 
que deu nome ao livro e que o próprio autor rotula de novela e cuja leitura recomenda logo de início, embora seja o antepenúltimo do livro.

Não há a menor dúvida de que esta novela é a glorificação de uma visão grotesca da vida, visão carnavalizada em que se ri para não se chorar, em que se desmitificam os valores tradicionais do homem e das instituições. Daí, talvez, a recomendação do autor, em sua postura irreverente e mordaz. A própria capa busca expressar, visualmente, o que nos será oferecido pela leitura.

O nome do anti-herói Florismundo, vulgo "Fló", "o menino que se recusava morrer", que atravessa a narrativa como semimorto, sempre rindo, rindo, desafiando as leis naturais da subsistência e que acaba sobrevivendo a toda a família, seu nome, pois, visualmente fragmentado, oferece amostra do processo de desintegração do ser, através de sua postura grotesca, mas, sem dúvida, simbólica ("Ele teve vida porque era o único que sonhava, que vivia olhando para o alto e sorrindo: tinha esperança"). O nome deste anti-herói aparece, na capa, desarticulado, em desnível de linhas e de cores:

\section{Flo Ris $\mathrm{M}$ \\ Undo \\ Periquito}

Vejam como o autor quis fazer sobressair o núcleo semântico $\mathrm{Ris}$ - construindo a imagem do riso.

Lida a novela, a epígrafe do conto resplandece como o farol a iluminar as trevas: "Um sonho é um dever do mundo".

Ao mesmo tempo, penso que se pode considerar esta novela uma mise-en-abîme de todo o livro, a partir dos pontos questionadores e dessacralizadores que levantam e que condensam a temática básica dos demais contos: a força dos impulsos autênticos da natureza do homem, o sonho como capacidade saudável de fuga da realidade, como propriedade cativa dos menos favorecidos; a dubiedade da ação da justiça frente às diferenças sociais, o primarismo de crenças e de conscientização social do homem sertanejo; ao mesmo tempo, a força dos valores míticos e telúricos a emoldurarem suas pequenas vidas e, sobretudo, paradoxal e grotescamente, o estímulo à luta, ao direito de viver, ainda que pelo sonho. 
Retomando Schwarz, ${ }^{5}$ reencontramos a idéia de que

A criação literária é um espelho entranhado, em que aparecem não só as conviç̧ões do intelecto, como as atitudes fundamentais que são o seu contexto, alcance e limite. Quando estas se modificam, uma visão do mundo é detalhadamente posta de lado, pois nada permanece intacto. Acompanhar-lhes a modificação é assistir ao desentulho, sem o qual não nasce uma cabeça nova.

A linguagem, em seu nível expressional, prepara os ganchos da trama, insinuando os pontos de conflitos:

Florismundo Periquito, quando nasceu, o pai Zé Periquito possuía disparate de filhos mortos e a morrer (p.75).

Segue-se a enumeração de nove projetos de vida, nove rebentos a proliferarem a miséria de vida do pai. São representados, numa transfiguração metafórica, como:

Um disparate de estrelas num céu coalhado de negrume (p.75).

As metáforas "disparate de estrelas" para vidas humanas que deveriam ser "vida" - potencial de força e energia e que não são e se esparramam num céu (símbolo de amor, paz, bonança) mas que está coalhado de negrume (miséria) - indicam o desnível semântico que prepara a leitura crítica.

Então, a própria expressão interage em relação ao conteúdo, fazendo germinar a decodificação crítica do leitor, aninhando seu potencial criador e gerando o momento do conflito.

E a temática básica nesta novela, orientando a elaboração da trama que se constitui de uma série de conflitos está, sem dúvida, na desesperada busca de vida desses "rebentos tristes", no embate entre o sonho e a dura realidade, na expectativa sempre frustrante de ser.

Zé Periquito, o pai, meses na estrada, carreando os filhos, entre eles o doente Fló com seu riso- crítico-vigilante e distante, a constituírem grotesco cortejo em busca de pouso seguro. "Zé Periquito andou seus suores", assim o narrador no-lo apresenta na sua trajetória candanga. Eleucina, a filha primeira a tombar nesta caminhada de retirantes, roída pelos vermes, tem retratação surrealista: 
Eleucina andava descarnada, sem sonho. Dizem que o sonho é que pesa mais no corpo, o sonho é um quinhão maior (p.76).

Distribuindo-se pela narrativa a célula germinal de sua tese, a carga dramática vai se espargindo pelo contexto da novela, contaminando, com seus índices expressionais, toda a linguagem que se recarrega do drama passional.

Portanto, não posso concordar com os termos da dedicatória "Ninguém poderá lucidamente dizer: aqui está uma linguagem, tal a desimportância dela diante das figuras humanas que busquei recriar" pois só ela, a linguagem, poderá nos dar a dimensão da proposta do escritor.

Interessante que, embora a novela Florismundo Periquito (cujo nome já sugere, por simbologia, a Flor do mundo, o sonho do mundo, o amor do mundo) encerre a maior carga dramática de todo o livro, este tom é disseminado ao longo dos demais contos, de tal modo que todos visem a mesma mensagem: desejo ou sonho, ou aspirações versus dura realidade ou contingências mesquinhas.

Mas também, por vezes, traindo voz de autor-implícito, com forte carga de crítica social, o sonho passa a ser o direito de uma categoria menos favorecida, recurso de fuga, como se constata no conto "Justiniano Pamplona", através da fala desta personagem:

O sujeito que não tem dinheiro, é muito sonhador; desatento de amizades é o sujeito cheio de dinheiro, descortina uma porção de ensejos gloriosos e um disparate de caminhos para o ganho. Mas o sujeito que tem muito dinheiro, mesmo que teve muita fome numa outra ocasião, agora não come mais. No sujeito que está ganhando muito dinheiro é ver um sujeito que está rezando para curar um mal muito grande. Deus não gosta muito do sujeito que está ganhando muito dinheiro. Mas, o caso é que o sujeito assim não se importa muito com Deus (p.54).

Mas, continuando com o desvelamento da trama de "Florismundo Periquito", vê-se a voz narradora universalizando o sonho, ainda que, aparentemente, na concepção daqueles desamparados. É quando apresenta a família: 
A familia podia ficar morando em Campo Maior. Não tinha presença. A mulher e os filhos sempre esperando terras, que Zé Periquito prometia. Não prometia, era sonho e eles pensavam que sonho era uma obrigação. Uma obrigação do mundo bem prometida e juramentada, como um dever do mundo (...)

Um sonho é um dever dos homens e do mundo (p.76).

Assim, entre sonhos e desalentos, prossegue a via-crúcis da família: prisão de uns, morte de outros, prostituição da filha e só Fló a resistir, metido num saco, carregado na rede, morrendo e (des)morrendo, a rir de tudo e de todos:

João Batista, o mano João Batista, ele punha sua atenção na vida de Fló; ele pondera a si que a morte de Fló era retardada por uma razão muito simples: ele está sempre rindo! João considera que o homem, nesta vida, tendo um remorso fica amuado e torcido, e o Fló não tinha razão pro remorso. João considera que o riso é feito para tocar a vida. Assim como Fló tocava a sua. E chamou João Batista ao pai e falou com o velho; este ficou pensando. E chamou João Batista à mãe $\mathrm{e}$ falou com ela na força do riso de Fló; o poder que tocava pra fora de seu corpo, todo o dia, a morte (p.79).

Chama a atenção, aqui, a questão da intertextualidade, configurada pela presença do discurso bíblico subjacente na estrutura da frase de ladainha - "E chamou João Batista ao pai"; "E chamou João Batista à mãe" - como para selar a marca deste discurso, a marca do solene nesta fala aparentemente tão sem importância.

$\mathrm{Ah}$ ! as fintas da linguagem!...

Aliás, a intertextualização do discurso bíblico se mostra, repetidas vezes, até nas imagens, como na visão de Fló, aliás, no pensamento de Fló, o anti-herói que pensa por imagens ou por falas que só nos chegam via narrador, ou pela voz da personagem João Batista (coincidências com o profeta anunciador!...). Assim, à página 79, outro exemplo:

Nessa madrugada, do saco, Fló ficou ouvindo a conversa dos seus e pensou mesmo naquela sua vida. Pensou numa mulher que viu em Piripiri, indo na estrada. Ela levava os filhos e uma carroça puxada por uma junta de bodes, levava o milho, abóboras, melancias. 
Penso que a lembrança da fuga da sagrada família - Nossa Senhora, São José, o Menino e o Jumento pelas estradas da Judéia, fugindo a Herodes que mandara decapitar as crianças - repentinamente me volta como índice simbólico: a estrada simbolizaria a busca de uma vida mais condigna, o início de uma atitude de reação; a mulher, a matriz da vida; o menino, os meninos, a continuidade desta vida e, da parte de Fló, o desesperado e esfomeado pau-de-arara, os alimentos representariam a garantia desta mesma vida. Então, através de recursos simbólicos, reforça-se a fábula, com lances aparentemente banais, mas que se somam na trajetória de conflitos a elaborarem a trama responsável pela temática: a trágica tentativa de viver.

A linguagem e seus mistérios!...

Mais adiante:

Todos sonharam, os filhos mais novos e os mais velhos. E também Fló sonhou, ele pensava nas juntas de bois bem amestradas e no carro. A velha Maria Gomes acrescentou que melhor do que as juntas de bois e o carro era a terra.

Se tivessem um pecúlio podiam adquirir um bom trato de terra $\mathrm{e}$ todos sonharam em ter um bom trato de terra. O Fló pensou na terra, na água e viu nos seus olhos a terra e viu a água correndo sobre a terra (p. 81).

Terra e água, elementos primários na criação da vida a escoarem uma voz bíblica no ato inicial do Universo. É tal a força da água que ela é capaz de salvar até um moribundo como Fló (alusão ao batismo cristão).

Levaram o irmão e o despiram à beira do córrego que corria na mata restinga. Fló, quando o sol ia alto, andava rindo. Deram-lhe mais banho e ele se tornou vigoroso dentro de sua enorme fraqueza (p. 88).

Há uma verdade mítica na saga desses retirantes. Uma força fatalista que delineia os seus caminhos mas que não impede os surtos de reação nestas almas bloqueadas pela miséria. Explosões da revolta que logo aborta como suas próprias vidas.

Perubina, a filha que tenta, na vida de aventura, a sua segurança pela ascensão econômica, pensando nos dissabores da família, conclui: 
Deus escreve certo por linhas tortas. Era triste: por que Deus não escrevia certo por linhas certas? mas era assim: sua mãe ensinara, sua vó. Mas tanto a mãe, como a vó Dó tiveram linhas tortas (p. 93).

Fló, o morto-vivo, o aleijado, o sábio, o herói patético, o profeta; Fló, o símbolo da força, da esperança, tem por armas: o sonho que o impele para a vida; o riso que o faz planar acima da pequenez dos fatos e o torna forte; o amor que o faz sensível ao toque dessa mesma vida paisagem, natureza, família, sua realidade, ainda que pequena e vil.

Seu corpo deformado é o anteparo das forças do mal que sua alma de "iluminado" é capaz de enfrentar e vencer. É o único a sobreviver; é como a terra, a água, o sol.

A capacidade de sonhar, já se viu, soma-se à capacidade de rir. Neste ponto, gostaria de fazer um confronto entre José Godoy Garcia e Dostoiévski quando este, em $O$ sonho de um homem ridiculo,${ }^{6}$ consegue, em bela demonstração de um "laconismo artístico-filosófico", pregar o universalismo desta obra e do traço marcante da menipéia- gênero satírico-carnavalizado, "que vem da Antiguidade e é capaz de penetrar em outros gêneros da Idade Moderna, sendo portador da cosmovisão carnavalesca na literatura até os nossos dias". ${ }^{7}$ Revela, ainda, excepcional capacidade para perceber e sentir, artisticamente, a idéia, como diz Bakhtin.

Ora, como se revela o intelectual, o artista, celeiro da idéia? Não seria pela sua forma de manifestação, pela sua linguagem?

Interessante que, em sua produção literária, também Dostoiévski "aproveitou amplamente as possibilidades artísticas do sonho em quase todos os seus matizes e variações, especialmente a importante variação dos sonhos de crise que levam o homem a renascer e a renovar-se". ${ }^{8}$ Não seria o sonho de Fló uma variação candanga deste sonho de crise? Não teria o sonho o destino de lhe oferecer uma meta de vida? Uma esperança de renovação? Mas, na área do riso, um traço mais acentuado parece distingui-los: o grau de conscientização. Bakhtin salienta a "plenitude de auto-consciência do 'homem ridículo': ele mesmo sabe melhor que ninguém que é ridículo". 9

Esta consciência não ocorre em Fló; ele simplesmente sabe, tem o juizo das coisas, vê o invisível, e sua patética família dá-lhe o crédito de sábio, em meio a esporádicas divagações: 
Todos continuaram pensando. Quem põe essa vontade que faz sair de seu corpo o riso? Quem faz ele ter esse poder de achar graça no mundo?

- Me parece que tudo tem uma razão, disse o pai.

- Ele é forte, disse João.

- É um menino, disse a mãe.

Ele vive morrendo porque o mundo é feito de muita morte. Mas ele vive na terra e gosta da água, disse João.

- O Fló tem muito segredo na sua alma, disse o pai (p. 79).

E se a dicotomia bobo-sábio e bobo-trágico - imagem cômicoséria-ambivalente da literatura carnavalizada - está presente no "homem ridículo, de Dostoiévski, em Fló ela se torna mais confusa e hermética, pendendo para uma simbolização quase mítica, não filosófica graças à ausência da formulação direta do pensamento do anti-herói que não fala, pelo menos até quase a cena final, como se verá adiante, que não divaga, a não ser por meio do discurso indireto, que não nos oferece uma formulação ao vivo de sua capacidade de reflexão, como no caso do homem ridículo de Dostoiévski, o que se comprova no exemplo a seguir:

E vi a verdade, não a imaginei em espírito, vi-a, digo que a vi, e a sua viva imagem encheu meu coração para sempre. ${ }^{10}$

As referências ao seu ato de pensar abrangem sempre aspectos os mais primários e imediatos quase que numa identificação de Fló com as verdadeiras forças vitais que seriam as nascidas da terra, da água, núcleos da vida, únicas fontes verdadeiras da razão de ser e às quais ele volta "pensando" repetidas vezes. A sua verdade prescinde de elucubrações cerebrais, mas, nem por isso, ele deixa de ser dono dela. Encontra-se, como o outro, isolado na sua postura, como é próprio dos sábios da menipéia, mas não por uma obsessão compulsiva; simplesmente por uma fatalidade. Ambos 'ilhados' nas suas posturas extravagantes que lhes determinam uma condição de 'solidão'. Penso que, para esclarecimento do que foi dito, deve-se iniciar pela apresentação de Fló:

Andavam com as tralhas às costas. O Fló dentro de saco onde fizeram buracos para melhor penetrar o ar. Era levado por uns e por outro, pelo pai e irmãos. Miúdo lagarto, um certo calango que vivia 
entremeio aos paus vivia morrendo, como Deus brincava com sua vida. Era levado no varal, dentro do saco, com os seus olhos na estrada, com sua alma de menino (p.77).

Se Fló, o anti-herói, é apresentado como símbolo de uma proposta de vida, as atitudes passivas e fatalistas que o distinguem resultarão, no final, dialeticamente, na vitória de uma postura diante da vida: a que prescreve o distanciamento dos fatos, a ironia (sempre o riso) no modo de encará-los e certa superioridade de visão em face do corriqueiro, como medida preventiva para se conseguir viver. Tudo isto atrelado a uma boa dose de capacidade de sonhar, de esperar, de sacudir a poeira, de amar.

Constata-se o modo como ele é apresentado em seus momentos de 'prováveis reações':

Vieram dizer de manhã que haviam descoberto o assassino. Com Fló, se deu que não se entregara à aflição. Engolira aquela desdita com o riso na sua face.

(...)

Tanto mano Joaquim, como João Batista, como Manoel Nonato, como Norberto, todos penavam o sacrifício e a desdita de suspeitos. Penavam a fome e a injúria (...) O Fló ria.

Por que Fló se abria naquele riso cheio de maldade naquela hora? Os soldados bêbados e, entre eles, um vestido com túnica amarela, o correame e as armas, de botas e esporas, se esqueceu das calças, as partes de fora. Ninguém notava, só Fló. Um soldado bêbado; era o mais desaforado (p. 78).

Aqui, faz sobressair, a voz narradora, a capacidade de Fló em apreender o ridículo do contexto, em perceber criticamente as circunstâncias em derredor. Mas, incrível: nenhuma vontade em alterar a realidade por qualquer tipo de ação. Apenas, a atitude zombeteira de quem sabe, certifica-se, e deixa rolar... Esta, sua capacidade de sonhar e de rir.

Depois, ainda na mesma página:

João Batista, o mano João Batista, ele punha sua atenção na vida de Fló; ele pondera a si que a morte de Fló era retardada por uma razão muito simples: ele está sempre rindo! (...) João considera que o riso é feito para tocar a vida. Assim como Fló tocava a sua. 
À instância de João Batista, toda a família se põe a aprender o "riso" com Fló.

(...) e todos se pegaram com muito esforço a rir. A mãe pensando que não tinha mais boca praquilo, tanto tempo sem rir que nem se lembrava mais, mas ela abria sua bocarra sem dente e todos puderam ver a tristeza do riso e todos perderam o alento no que desejavam. Tudo só de ver a bocarra da mãe esperançosa. E se resignaram no silêncio, mas a mãe largava um riso que era uma maldade do mundo. E eles ficaram pensando na vida da mãe (p.80).

Está aí um momento cruciante da elaboração da trama perante a proposta da novela, perante sua temática que, já vimos, insiste em mostrar o desesperado empenho de tentar 'viver', quando viver parece um direito fundamental.

O narrador, ao mostrar o esforço conjunto da família em adestrar-se com a arma de Fló, o riso, para eles e por conselho de João Batista, o único meio de sobreviver, de vencer as intempéries, o narrador, pois, bosqueja o real com as cores da sátira, da ironia, elementos que dilatam as fronteiras do drama vivido por esta réstea de seres e, assim, aprofunda as dimensões da tragédia que é o habitat comum de todos eles.

Portanto, sátira e tragédia compondo um só recurso dramático, estabelecendo um explosivo gênero surrealista que possa abarcar os elementos narrativos nas engrenagens das sucessivas desmontagens do ser.

E, tudo isto, amalgamado por uma unidade dinâmica que é a linguagem da obra: expressão e conteúdo amarrados na soldagem literária de um núcleo temático energético, traduzindo a impetuosidade criadora do narrador.

Então, estas personagens dramáticas assim se intitulam porque assim foram moldadas, através dos conflitos, enroladas nos novelos da trama, reafirmando, sempre, uma proposta temática: foram moldadas, pois, pela linguagem, atendendo a uma proposta do criador que, infelizmente, neste caso, a desvaloriza e desmerece.

Para finalizar, um gran finale. À medida de viver de Fló, traduzindo uma visão carnavalizada, soma-se uma outra, agora vinculada à figura do velho pai (força patriarcal, discurso da moral cristã). 
E José Periquito, o pai, encarna a capacidade de trabalhar, encarna os verdadeiros e tradicionais valores, portanto, à visão crítica e sonhadora de Fló, acrescenta-se, agora, a ação do trabalho - entendido como o empenho, a luta pela vida - e 'reabilita' a novela de sua postura desmistificadora e irreverente.

A terra não é só o seu corpo, com os rios e o verde as chuvas e o vento. Ela é mais. É o ser vivente. Não há nada que faça a terra morrer. Eis o trabalho, o trabalho dá uma energia de vida no mundo que faz com que o mundo não pereça.. O velho Zé Periquito olha para sua mão. $\mathrm{O}$ sol já se ia; o barulho das águas vivificava o silêncio do entardecer. Periquito esquece de si e dos filhos e fica pensando na vida das águas.

- Não riu hoje, Fló - falou Cinira.

- Inda vou rir, vou esperar meu pai chegar (p.106).

Portanto, neste trecho, prosa rescendendo poesia, como num milagre, pela artimanha da linguagem (num estereótipo da técnica do diálogo) soou ao vivo o pensamento de Fló, como uma fala, a primeira de toda a narrativa. Surgiu bosquejando a figura que resplandece como uma imagem do trabalho, como potencial de vida e de luta: o vulto do pai:

(...) as mãos do velho Zé Periquito eram mãos que punham energia no mundo. Nas cidades do médio e alto São Francisco sempre corria lenda do menino que não sabia morrer, mas ninguém via e encontrava esse menino (p. 106).

Cheguei a pensar que a projeção do vulto do pai como símbolo de nova força a 'trabalhar' a trama da novela, a distorcer o seu clima carnavalesco, pudesse ser interpretado em nível metalingüístico. Nele, a terra simbolizaria a matéria da obra literária (a realidade a ser transfigurada); o vulto do pai, seu sonho, a inspiração, a força interior sem a qual não há legítima produção literária; enfim, a mão representaria o labor, a consciência do fazer literário capaz de transformar a matériaprima selecionada em obra de arte moderna, fruto de inspiração e artesanato. Mas, talvez, na visão crítica muito exacerbada de nosso escritor, eu fosse acusada de estar vendo fantasias... 
De qualquer modo, em cena final, a figura de Fló se firma em definitivo como uma estrela em ascensão; ele é tratado, como no momento inicial da apresentação, e, em poucas passagens da narrativa, pelo nome inteiro - Florismundo - e ele fala:

Cinira falou com Fló sobre o assunto [tratava-se da pretensão mal intencionada de um pretendente] e Fló riu afirmando [vejam o verbo dicendi, na verdade, um sentiendi porque traduz não só a fala, mas o modo desta fala], que o tocador de sino mais o soltador de foguetes da festa de Bom Jesus [os pretendentes em questão] eram sujeitos de má índole; ele queria ver a cara deles. Cinira trouxe os dois, que tinham cara de santo, e Florismundo [alçado, então, a conselheiro da irmã] cuspiu na cara deles. Se despediram de Bom Jesus, foram embora, e, certa vez, na estrada de Januária, Fló disse à irmã que tinha vontade que ela se casasse com um pescador. Cinira também imaginou que seria bom que ela tivesse sorte e arranjasse um casamento bem igual ao que o irmão sonhava. Quando Cinira morreu, Fló ficou sozinho no mundo.

Reabilitada a fala, ele é ser por inteiro e reage.

Aí está, senhor poeta e prosador, a saga de uma família de retirantes, o que não seria novidade em nossa literatura. $\mathrm{O}$ que a faz notada é a profunda exploração do interior destes seres, arrolados em processos carnavalizados na luta pelo direito de viver.

Tem-se, então, senhor poeta e prosador, uma majestosa novela que só é majestosa e só é novela porque assim foi elaborada e porque sua trama emerge esteticamente emoldurada pelas tramas da linguagem de um cérebro criador. Ratificando a minha proposta, da performance da linguagem na manifestação do produto estético, reproduzo, aqui, um trecho do poema que fecha o último livro de poesia de José Godoy Garcia, recentemente lançado ( $O$ flautista e o mundo sol verde $e$ vermelho. Brasília: Thesaurus, 1994):

A poesia está solta no mundo, sim, mas o que é de uma bondade sem fim (sempre um redemoinho, um Florismundo, e há sempre um adormecido ninho)

é a poesia que se adere e guarda no coração humano. É a poesia boa, 
a que se ferve, resguarda e voa

no férvido doce coração do mundo.

\begin{abstract}
The present essay aims to discuss the problems related to the approach to literary phenomenon and the role of language within it.
\end{abstract}

\title{
NOTAS
}

1 BARTHES, Roland. $O$ grau zero da escritura. p. 124

2 SCHWARZ, Roberto. A sereia e o desconfiado. p. 101

3 CROCE, Benedetto. Estética. 101

4 HATHERLY, Ana. O espaço crítico. p. 118

5 SCHWARZ, Roberto. A sereia e o desconfiado. p. 93

6 BAKHTIN, Mikhail. Problemas da poética de Dostoiévski. p. 128

7 Idem, p. 98

8 Idem, p. 128

9 Idem, p. 130

10 Idem, p. 129

\section{REFERÊNCIAS BIBLIOGRÁFICAS}

BARTHES, Roland. O grau zero da escritura. São Paulo: Cultrix, 1974. BAKHTIN, Mikhail. Problemas da poética de Dostoiévsky. Rio de Janeiro: Forense Universitária, 1981.

CROCE, Benedetto. Estética. Buenos Aires: Ediciones Nueva Visión, 1979.

HATHERLY, Ana. O espaço crítico. Lisboa: Ed. Caminho, 1979.

SCHWARZ, Roberto. A sereia e o desconfiado. Rio de Janeiro: Civilização Brasileira, 1965. 